\title{
«Bien dire et bien aprandre», La volonté didactique dans la littérature médiévale (tome I)
}

\section{Maria Colombo Timelli}

\section{(2) OpenEdition}

1 Journals

\section{Édition électronique}

URL : http://journals.openedition.org/studifrancesi/1225

DOI : 10.4000/studifrancesi. 1225

ISSN : 2427-5856

Éditeur

Rosenberg \& Sellier

\section{Édition imprimée}

Date de publication : 1 décembre 2015

Pagination : 559-560

ISSN : 0039-2944

\section{Référence électronique}

Maria Colombo Timelli, « «Bien dire et bien aprandre», La volonté didactique dans la littérature médiévale (tome I) », Studi Francesi [En ligne], 177 (LIX | III) | 2015, mis en ligne le 01 décembre 2015, consulté le 11 janvier 2021. URL : http://journals.openedition.org/studifrancesi/1225 ; DOI : https://doi.org/ 10.4000/studifrancesi.1225

Ce document a été généré automatiquement le 11 janvier 2021.

\section{(c)}

Studi Francesi è distribuita con Licenza Creative Commons Attribuzione - Non commerciale - Non opere derivate 4.0 Internazionale. 


\title{
«Bien dire et bien aprandre», $L a$ volonté didactique dans la littérature médiévale (tome I)
}

\author{
Maria Colombo Timelli
}

\section{RÉFÉRENCE}

«Bien dire et bien aprandre», Revue de Médiévistique. La volonté didactique dans la littérature médiévale (tome I) 29, 2013.

1 Ce volume réunit un premier groupe des communications données lors des journées d'études que l'équipe Alithila de l'Université de Lille 3 a organisées en décembre 2011: comme le rappellent Sarah BAUDELLE-MICHELS et Marie-Madeleine CASTELLANI dans l'Avant-propos (p. 5-9), il s'agissait alors de réfléchir sur la «tentation», voire sur la «volonté» didactique omniprésente dans des œuvres n'ayant pas pour but premier d'instruire ou de former leurs destinataires, mais plutôt de les distraire.

2 S'attachant au Roman de Rou de Wace, Françoise LAURENT relève que le changement de mètre, de l'alexandrin à l'octosyllabe, coïncide avec le changement de source (du prosimètre De moribus de Didon de Saint-Quentin, à la prose de Guillaume de Jumièges) et avec une accentuation de la dimension didactique; par ailleurs, les goûts de la cour anglo-normande au XII siècle ne sont sans doute pas étrangers à l'adoption du mètre adopté pour la littérature didactique en général (vies de saints, romans antiques et historiographie) (Un vecteur formel du discours didactique: l'octosyllabe dans le "Roman de Rou" de Wace, pp. 17-30).

3 Aimé PETIT met en relief la volonté didactique - affichée dès les prologues-qui se déploie dans quelques passages descriptifs des romans de la triade antique: descriptions de la tente d'Adraste dans Thèbes, du char d'Amphiaraüs dans Enéas, de l'Orient dans Troie (La volonté didactique dans les romans d'Antiquité, pp. 31-49). 
4 Sandrine LEGRAND s'interroge sur les raisons qui ont amené Christine de Pizan à faire d'Hector à la fois le destinataire de son Epistre et le sujet de nombre des exempla évoqués. De fait, la figure du héros troyen est double et paradoxale: ancêtre de la maison royale de France et guerrier troyen destiné à une fin tragique, il incarne par là une mise en garde contre la démesure (Comment faire d'un héros un modèle de vertu? Hector dans l'"Espistre Othea" de Christine de Pizan, pp. 51-64; dossier iconographique aux pp. 65-70).

5 Observant la fréquence des chastoiements dans les chansons de geste lors du départ des jeunes héros de leur foyer familial, Sarah BAUDELLE-MICHELS consacre une analyse aussi savante qu'amusée à des passages tirés de quelques chansons de révolte, Doon de Mayence et Renaut de Montauban en prose (version bourguignonne) en particulier. Tout en constituant des passages dépourvus de fonction dramatique, et dont le contenu est partagé entre morale chrétienne et simples règles de comportement, les chastoiements gardent une valeur littéraire certaine par la fonction rétrospective qu'ils assument au moment où le drame se produit (Les 'chastoiements' dans les chansons de geste de la révolte, pp. 73-84).

6 La visée didactique des chansons du cycle de Guillaume ne fait pas de doute: Sonia MARTEAU souligne en particulier les aspects rattachés à une réflexion politique centrée sur le rôle du roi, des barons, des ecclésiastiques, et surtout sur la nécessité d'établir et de conserver un équilibre fondé sur la justice ( $\mathrm{La}$ volonté didactique dans le cycle de Guillaume d'Orange, pp. 85-101).

7 Caroline CAZANAVE compare les visées didactiques dans deux œuvres fort lointaines dans le temps: les deux Moniages Guillaume du $\mathrm{XII}^{\mathrm{e}}$ siècle et la réécriture en prose réalisée pour la jeunesse française par Louis Gabriel-Robinet en 1970-71; elle ne peut que constater que les types d'enseignements affichés dans les textes répondent à des exigences et à des principes différents: dans les Moniages, Guillaume offre le modèle d'un héros devenu saint à la fin de sa vie, alors qu'au $x^{e}$ siècle il s'agit plutôt de promouvoir la connaissance du Moyen Âge à travers ses œuvres et un vocabulaire propre (Guillaume et les voies didactiques de ses "Moniages", pp. 103-117).

8 C'est à deux recueils de Miracles de la Vierge, celui d'Adgar (vers 1165) et celui de Gautier de Coinci (1218-1233) que Jean-Louis BENOIT consacre ses réflexions: si l'intention didactique est intrinsèque au genre même, il est alors intéressant d'analyser les modalités d'insertion de ce discours, ainsi que le recours à des stratégies et procédés propres de la littérature profane, en l'occurrence courtoise (Enseignement et littérature dans "Les Miracles de Notre-Dame" de Gautier de Coinci et "Le Gracial" d'Adgar, pp. 121-138).

Marie-Madeleine CASTELLANI propose une lecture de La Manekine en rapport avec les motifs que Philippe de Remi a tirés des contes folkloriques sous-jacents: elle peut ainsi souligner, sur le plan stylistique et formel, l'emploi fréquent des proverbes et le rôle qui leur est assigné, et sur le plan narratif le relief pris par les personnages, devenus les modèles d'une sainteté toute lä̈que (Philippe de Remi ou la tentation du sermon, pp. 139-149).

10 L'article co-signé par Stéphanie LE BRIZ et Géraldine VEYSSEYRE est divisé en deux volets. Est d'abord analysée la structure du Pèlerinage de l'âme, sa tripartition, sa difficulté croissante, ainsi que la diversification et multiplication des domaines abordés, qui dénoncent une sorte d'ambition encyclopédique de la part de Guillaume. L'étude s'élargit ensuite à la lecture et réception de l'œuvre à travers l'examen des marginalia 
qui marquent 29 des 46 manuscrits conservés: très divers entre eux, ils partagent néanmoins un respect absolu pour le contenu, ainsi qu'une attention marquée pour les aspects didactiques du texte ('Sens faire rien, pou vau li sens': mise en œuvre et réception de l'ambition didactique de Guillaume de Digulleville en son "Pèlerinage de l'âme" (ca 1355), pp. 151-180).

11 Destiné à la dévotion privée, le commentaire sur les sept psaumes pénitentiels possède déjà une longue tradition au $\mathrm{xv}^{\mathrm{e}}$ siècle, tant en latin qu'en langue vulgaire. La lecture allégorisée qu'en propose Christine de Pizan, objet de la contribution de Bernard RIBÉMONT, correspond à une profonde vision didactique, qui s'exprime dans les enseignements moraux et théologiques appuyés tant sur l'Ancien que sur le Nouveau Testament, mais aussi par des réflexions politiques (Entre pénitence privée et didactisme: Les "Sept Psaumes allégorisés" de Christine de Pizan, pp. 181-197).

12 Élisabeth PINTO-MATHIEU étudie le rapport entre la réflexion théologique de Jean Gerson et sa visée didactique telle qu'elle se révèle par exemple dans le sermon Videmus nunc per speculum (1402) inspiré par la première Épître aux Corinthiens de saint Paul: l'homélie prend la forme d'un dialogue intérieur entre l'Âme et sa sœur Raison, qui aboutira à une connaissance et contemplation de Dieu et de la Trinité rendue possible par la dévotion et l'amour (Le "Videmus nunc per speculum", un sermon didactique de Jean Gerson, pp. 199-211). 